\title{
Protection of plants from ambient ozone by applications of ethylenediurea (EDU): A meta-analytic review
}

\author{
Zhaozhong Feng $^{\mathrm{a}, *}$, Shuguang Wang ${ }^{\mathrm{b}}$, Zoltan Szantoi ${ }^{\mathrm{c}}$, Shuai Chen ${ }^{\mathrm{a}}$, Xiaoke Wang ${ }^{\mathrm{a}}$ \\ a State Key Laboratory of Urban and Regional Ecology, Research Center for Eco-Environmental Sciences, Chinese Academy of Sciences, Beijing 100085, China \\ ${ }^{\mathrm{b}}$ Department of Environmental Science and Engineering, Beijing University of Chemical Technology, Beijing 100029, China \\ ${ }^{\mathrm{C}}$ School of Forest Resources and Conservation, University of Florida, Gainesville, FL 32611-0565, USA \\ EDU effectively protect plants against ambient ozone.
}

\section{A R T I C L E I N F O}

\section{Article history:}

Received 9 February 2010

Received in revised form

3 July 2010

Accepted 13 July 2010

\section{Keywords:}

Ozone

EDU

Plant growth

Photosynthesis

Yield

\begin{abstract}
A B S T R A C T
A meta-analysis was conducted to quantitatively assess the effects of ethylenediurea (EDU) on ozone $\left(\mathrm{O}_{3}\right)$ injury, growth, physiology and productivity of plants grown in ambient air conditions. Results indicated that EDU significantly reduced $\mathrm{O}_{3}$-caused visible injury by $76 \%$, and increased photosynthetic rate by $8 \%$, above-ground biomass by $7 \%$ and crop yield by $15 \%$ in comparison with non-EDU treated plants, suggesting that ozone reduces growth and yield under current ambient conditions. EDU significantly ameliorated the biomass and yield of crops and grasses, but had no significant effect on tree growth with an exception of stem diameter. EDU applied as a soil drench at a concentration of 200-400 mg/L has the highest positive effect on crops grown in the field. Long-term research on full-grown tree species is needed. In conclusion, EDU is a powerful tool for assessing effects of ambient $\left[\mathrm{O}_{3}\right]$ on vegetation.
\end{abstract}

(c) 2010 Elsevier Ltd. All rights reserved.

\section{Introduction}

Tropospheric ozone $\left(\mathrm{O}_{3}\right)$ is currently considered as the most important phytotoxic photochemical air pollutant in most parts of the world, as it causes significant injury and damage to both agricultural and native species (Ashmore, 2005; Booker et al., 2009; Emberson et al., 2009; Feng and Kobayashi, 2009; Feng et al., 2008; Fuhrer and Booker, 2003; Mills et al., 2010; Morgan et al., 2003; Wittig et al., 2009). Due to rapid economic development during the past decades, surface $\mathrm{O}_{3}$ increased at an annual rate of $0.5 \%-2 \%$ (Vingarzan, 2004) and has now reached a global mean of approximately $50 \mathrm{ppb}$ (8-h summer seasonal average) (The Royal Society, 2008). While $\mathrm{O}_{3}$ is often originated in urban areas, it can be transported long distances on prevailing winds. High $\mathrm{O}_{3}$ concentration $\left(\left[\mathrm{O}_{3}\right]\right)$ is often reported in rural and remote regions which affect the growth and productivity of agricultural crops and forests (Agrawal et al., 2005; Ashmore, 2005; Wang et al., 2007).

Some of the negative effects induced by ozone include decreased chlorophyll contents, decline in photosynthesis and stomatal conductance, altered antioxidant levels, accelerated leaf senescence, and reductions in total plant biomass and nutritive yield (Booker et al., 2009; Feng and Kobayashi, 2009; Feng et al.,

\footnotetext{
* Corresponding author.

E-mail address: zhzhfeng201@hotmail.com (Z. Feng).
}

2008; Morgan et al., 2003; Piikki et al., 2008b; Wittig et al., 2007, 2009). In a meta-analysis study, ambient $\mathrm{O}_{3}$ caused a mean yield loss of $11.3 \%$ in the range from $5 \%$ to $19 \%$ in the six major food crops including cereals, grain legumes and tubers (Feng and Kobayashi, 2009). For woody plants, a meta-analysis on 100 studies indicated that ambient $\mathrm{O}_{3}$ ( $40 \mathrm{ppb}$ on average) significantly reduced the total biomass of trees by $7 \%$ compared with trees grown in chambers with charcoal-filtered controls (Wittig et al., 2009).

In these two meta-analysis, most of the results were from open top chambers (OTCs) which is the most frequently used and convenient method. However, OTCs have effects of their own, such as differences in microclimate, fixed gas flow and limited size of the chambers, which contributed to an over- or under- estimate of the $\mathrm{O}_{3}$ effects on plants (Nussbaum and Fuhrer, 2000; Piikki et al., 2008a). In the recent decade, open-air fumigations (FACE systems) have been constructed and used at several locations to expose larger trees, crops and grasses (e.g. Feng et al., 2010; Holland et al., 1995). Although this technique is mostly near to true ambient conditions, the whole system is very expensive and requires high-level technology. Therefore, it is quite necessary to develop a method to assess the effects of ambient $\mathrm{O}_{3}$ on plants in an economical and easilyoperated way, especially in developing countries and remote regions.

Since the first description in the study of Carnahan et al. (1978), Ethylenediurea (N-[2-(2-oxo-1-imidazolidinyl) ethyl]-N'-phenylurea), abbreviated as EDU, has been extensively used in chamber 
and field studies to assess the impacts of ambient $\mathrm{O}_{3}$ on cultivated and native species (Manning, 2000; Paoletti et al., 2009). In the United Nations/Economic Commission for Europe International Co-operative Program on the effects of air pollution (primarily ozone) and other stresses on crops and non-woody plants (UN/ECE ICP-Vegetation, formerly UN/ECE ICP-Crops), EDU has been used to investigate crop responses to ambient ozone in many European countries (Sanders et al., 1992).

EDU was applied as soil drenches, foliar sprays and stem injections or gravitational infusion under ambient conditions without the use of chambers. This approach does not modify the environment in which the plants are grown, a problem associated with chambers with air filtration systems (OTCs) (Ball et al., 1998). EDU was also used as a potential research tool in remote areas where electricity is not available (Agrawal et al., 2005; Ali and AbdelFattah, 2006; Tiwari et al., 2005). Numerous results indicated that EDU significantly prevented $\mathrm{O}_{3}$-casued injury, inhibited premature senescence and maintained the photosynthetic pigments in plants (Agrawal et al., 2005; Paoletti et al., 2008, 2009). However, the protection of EDU against $\mathrm{O}_{3}$ varied with plant type, cultivar/line/ clone (e.g. Singh et al., 2009) and application method (e.g. Roberts et al., 1985).

Meta-analysis is a quantitative approach that estimates a mean relative response from individual studies to find general trend and differences. This approach developed rapidly since it was successfully introduced into the field of ecology and evolutionary biology in the late 1990's (Lei et al., 2007; Osenberg et al., 1999). Lei et al. (2007) described the principles, steps, advantages and disadvantages of meta-analysis and reviewed its application in the field of climate change e.g. the responses of ecosystem to global warming, rising $\left[\mathrm{CO}_{2}\right]$ and elevated $\left[\mathrm{O}_{3}\right]$, the effects of land use and management on climate change.

In this study, we used the meta-analytic technique to quantitatively assess the overall effects of EDU on plants exposed to ambient ozone conditions, by comparing EDU-treated plants with non-treated ones. Our aims were to (1) summarize and synthesize the results of the numerous EDU studies in terms of visible foliar injury, growth, physiology and productivity under ambient ozone conditions; (2) to determine whether the protection of EDU on crops, grasses and tree species was affected by rooting environment, EDU application method and its concentrations; and (3) to compare results with other meta-analysis based on chamber studies.

\section{Materials and methods}

\subsection{Data collection}

Using the Web of Science (Thompson-ISI, Philadelphia, PA, USA), a database of the effects of EDU on the visible injury, growth, productivity and physiology of plants was built up by surveying the peer-reviewed literature published before 2010 and by cross-checking the list of cited references of narrative review. To determine the effects of EDU treatment under ambient $\left[\mathrm{O}_{3}\right]$, those articles and measurements were included in this analysis if they met the following criteria: 1) experimental ozone treatment was ambient air with an average of daily $\left[\mathrm{O}_{3}\right]$ between 30 and $85 \mathrm{ppb}$ during the EDU experiment; 2) the duration of the experiment was one growing season for agricultural or horticultural crops, eight weeks for clover (sampled every four weeks), and at least one year for trees; 3) visible injury was based on the percentage of $\mathrm{O}_{3}$-injured leaf in total leaves.

After selection, a total of 50 publications were used for this meta-analysis (Appendix S1), in which 5 papers focused on plants exposed to ambient air in OTCs and 45 papers exposed to open-air. Species used in this analysis, covering crops, grasses and trees are summarized in Table 1 . Parameters were considered independent if the data was obtained from separate experiments or from different treatments within a single study (e.g. different EDU concentration, EDU application method, experimental years, species, and cultivars or lines). For those physiological variables such as chlorophyll content, photosynthesis rate, stomatal conductance, the measurements were assumed independently from different dates in the same experiment. Visible injury, growth and yield data were only used from final harvest
Table 1

List of species included in this meta-analysis.

\begin{tabular}{|c|c|c|}
\hline Crop (35 $)$ & Grasses (6) & Trees (9) \\
\hline $\begin{array}{l}\text { Arachis hypogaea }\left(1^{\mathrm{b}}\right) \\
\text { Beta vulgaris }(1) \\
\text { Brassica rapa (1) } \\
\text { Echinacea purpurea (1) } \\
\text { Glycine max (5) } \\
\text { Lycopersicon esculentum (2) } \\
\text { Nicotianu tabacum (1) } \\
\text { Oryza sativa (1) } \\
\text { Phaseolus vulgaris (10) } \\
\text { Raphanus sativus (2) } \\
\text { Rudbeckia laciniata (1) } \\
\text { Solanum tuberosum (4) } \\
\text { Triticum aestivum (4) } \\
\text { Vicia faba (1) } \\
\text { Vigna radiata (2) }\end{array}$ & $\begin{array}{l}\text { Trifolium pratense (1) } \\
\text { T. repens (4) } \\
\text { T. subterraneum (3) }\end{array}$ & $\begin{array}{l}\text { Fraxinus excelsior (3) } \\
\text { Hibiscus syriacus (1) } \\
\text { Pinus taeda (2) } \\
\text { Populus } \times \text { euramericana } \\
\text { 'I-214' (1) } \\
\text { Populus deltoides } \times \\
\text { maximowiczii 'Eridano' } \\
(1) \\
\text { Populus nigra (1) } \\
\text { Prunus serotina }\end{array}$ \\
\hline
\end{tabular}

a The number of total studies on investigated plant type.

b The number of studies on each species.

measurements. Mean value for each variable was taken directly from tables or text, when reported. Data given only in the figures were digitized by using GRAFULA software (Wesik SoftHaus, St. Petersburg, Russia).

To explain the variation in some variables response to EDU, the data were divided into four categories: (1) plant type, including tree, grasses and crops; (2) rooting environments ('pot'-rooted within a container or 'field'-rooted directly in the earth); (3) EDU application method, including soil drench and foliar spray, but with an exception of stem injection due to limited observations; (4) EDU concentrations, classified as A: $\leq 200 \mathrm{mg} / \mathrm{L}, \mathrm{B}: 201-400 \mathrm{mg} / \mathrm{L}, \mathrm{C}: 401-600 \mathrm{mg} / \mathrm{L}, \mathrm{D}: \geq$ $601 \mathrm{mg} / \mathrm{L}$. Several comparisons within each category (excluding plant type) were made on the different criteria basis, which eliminated, in some degree, the possible effects by unequal distribution of other factors in the datasets. The interval of EDU application ranged from ten days to three weeks, but most studies applied EDU every two weeks from seedling to final harvest. The times of EDU application depended on the growth span of plants with a range from two to ten times. Therefore, the effects of application times were not included in this paper.

\subsection{Meta-analyses}

The meta-analysis was carried out by using the MetaWin 2.0 statistical software (Rosenberg et al., 2000). To estimate the effects of EDU treatment on plants as a proportionate change relative to non-EDU (water) treated plants, the natural log of the response ratio $(r)$ was used as the metric for analysis, where $r$ is the ratio of the mean in the EDU treatment $(\mathrm{Xt})$ divided by the mean in the control of non-EDU treatment (Xc) (Hedges et al., 1999; Rosenberg et al., 2000). Effect sizes are reported as the antilog $r$ converted to the mean percentage changes from control as $(r-1) \times 100 \%$ (Curtis and Wang, 1998; Morgan et al., 2003). Positive percentage changes indicate an increase in the plant variable in response to EDU treatment, whereas negative values indicate a decrease.

About 60\% studies did not report data that would allow computation of sample variance (standard deviations or standard errors with replicate size), therefore an unweighted fixed-effects model was used to estimate the mean effects of EDU on various variables. In this model, 95\% confidence intervals $(\mathrm{CI})$ around the mean effect size was calculated by resampling the data using 9999 bootstrap replicates for each analysis (Adams et al., 1997). Estimates of the effect size were assumed to be significant if the 95\% CI did not overlap with zero (Curtis and Wang, 1998). For multiple comparisons, groups were considered to differ significantly if their $95 \% \mathrm{CI}$ did not overlap, providing a conservative test of group differences (Feng et al., 2008). Each categorical level was included in the analysis if there were at least 10 observations or more than 5 observations but originated from at least two independent studies, which follows other meta-analysis studies on trees and crops (Feng and Kobayashi, 2009; Wittig et al., 2009).

\section{Results}

\subsection{Overall effects of EDU application}

The effects of EDU on all variables, including $\mathrm{O}_{3}$-caused visible injury, growth, yield and physiological parameters were presented as a percentage change from non-EDU treatment (Fig. 1). Across all studies, EDU application significantly reduced foliar injury against ambient $\mathrm{O}_{3}$ by $76 \%$ with a $95 \% \mathrm{CI}$ of $71-80 \%$, in comparison with non-EDU treated plants (Fig. 1). EDU significantly increased root 


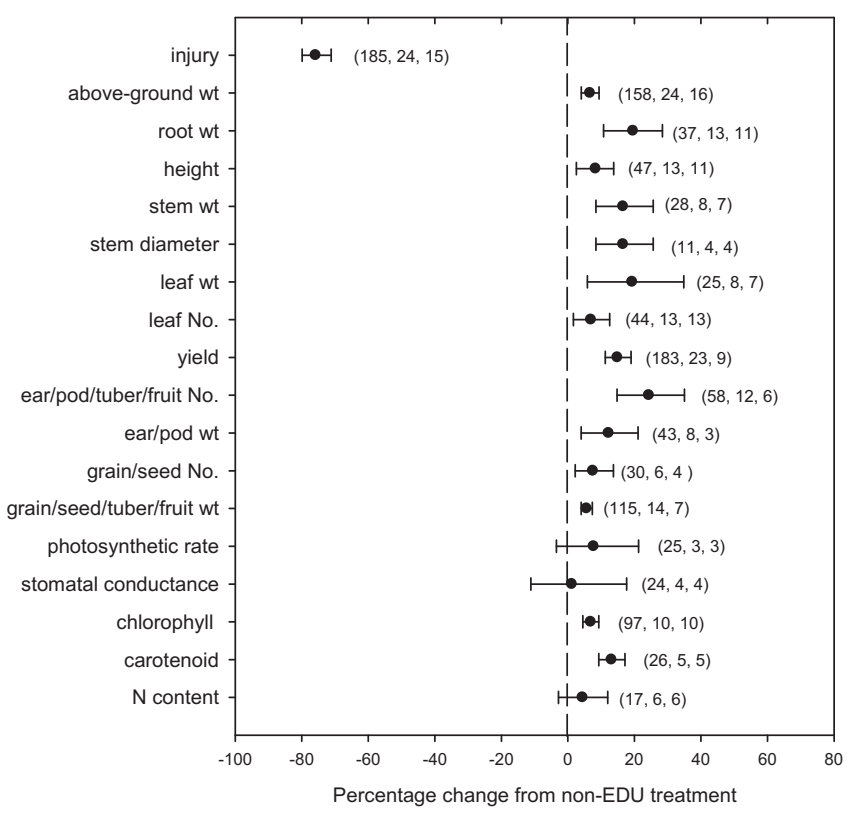

Fig. 1. Effect of EDU on injury, growth, biomass, yield and its components, physiology of plants grown in ambient $\left[\mathrm{O}_{3}\right]$. Symbols represent the mean percentage change induced by EDU relative to non-EDU treatment and the bars show the $95 \%$ confidence intervals (CIs). The values in the parentheses showed the number of observations, individual studies and species, respectively.

biomass (20\%) more than above-ground biomass (6.7\%). The remarkable increase in above-ground biomass was from a combination of taller height $(+8 \%)$ with larger stem weight $(+17 \%)$, increased leaf number $(+7 \%)$ and leaf biomass $(+19 \%)$. Stem diameter in trees was also increased by $13 \%$ significantly after EDU application. Photosynthetic rate (Pn), chlorophyll (Chl) and carotenoid (Car) contents in EDU-treated plants were significantly higher by $8 \%, 7 \%$ and $13 \%$ than that in non-EDU plants, respectively. However, EDU did not significantly alter stomatal conductance (gs) and $\mathrm{N}$ content of plants exposed to ambient $\left[\mathrm{O}_{3}\right]$ (Fig. 1).

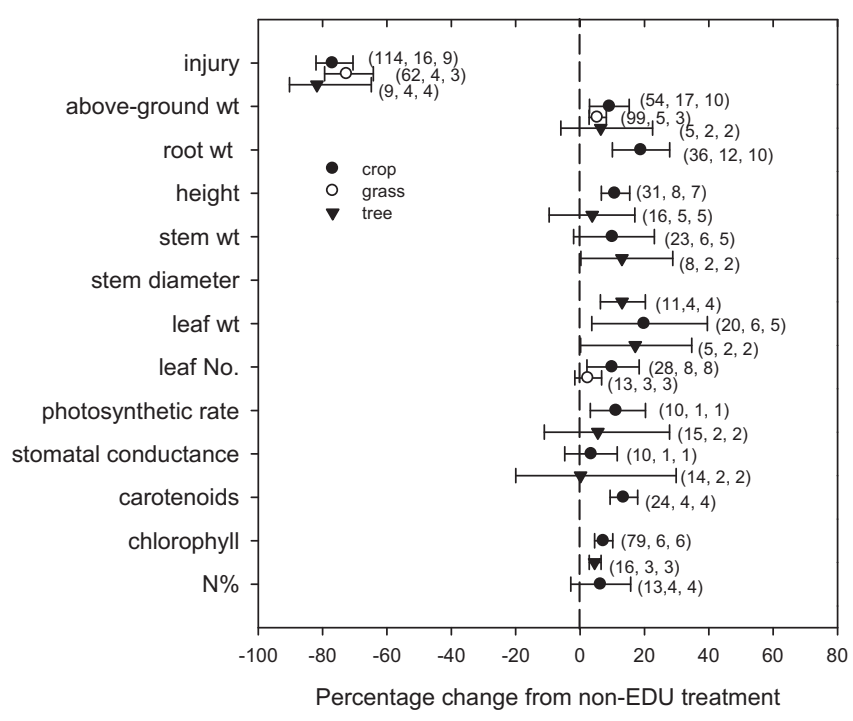

Fig. 2. Effects of EDU on growth, biomass and physiology of different plant types exposed to ambient $\left[\mathrm{O}_{3}\right]$. Symbols represent the mean percentage change induced by EDU relative to non-EDU treatment and the bars show the 95\% confidence intervals (CIs). The values in the parentheses showed the number of observations, individual studies and species, respectively.
For crops, EDU significantly increased yield by $15 \%(n=185)$ for plants grown in ambient $\left[\mathrm{O}_{3}\right]$. Ear/pod/tuber/fruit number per plant, individual grain/seed/tuber/fruit weight and grain/seed number per ear/pod in EDU-treated plants were $24 \%, 5.6 \%$ and $7.5 \%$ higher than those in non-EDU treated ones, respectively (Fig. 1).

\subsection{The response of plant types to EDU}

EDU significantly decreased visible injury by $77 \%, 73 \%$ and $82 \%$ for crops, grasses and trees, respectively. Biomass, pigment contents and Pn were significantly increased on crops when treated by EDU, but had no effects on gs, foliar $\mathrm{N}$ content and stem biomass. EDU significantly increased biomass of grasses despite having no effects on the number of leaves. Stem diameter and Chl were significantly increased on trees when EDU was applied, whereas had no effects on gs, Pn, height and above-ground biomass.

\subsection{The effect of rooting environment}

Generally, plants grown in the field had less visible injury and greater increases in most variables due to EDU application, in comparison with those grown in pots (Fig. 3). Significant difference was observed in leaf number and Car content (Fig. 3A), stem weight and root biomass (Fig. 3B) and Car content (Fig. 3C, D). From the response of those crops applied as a soil drench at a $201-400 \mathrm{mg} / \mathrm{L}$ EDU, the increase in Car content of plants rooted in the field was 3fold of those rooted in the pots (Fig. 3D).

\subsection{The effect of EDU application method}

All available variables indicated EDU applied as soil drench significantly ameliorated plant growth but only few parameters showed significant positive effects of EDU applied as foliar spray (Fig. 4). Relative to foliar spray, soil drench of EDU induced significant increases in plant height, root biomass and ear/pod/tuber No.

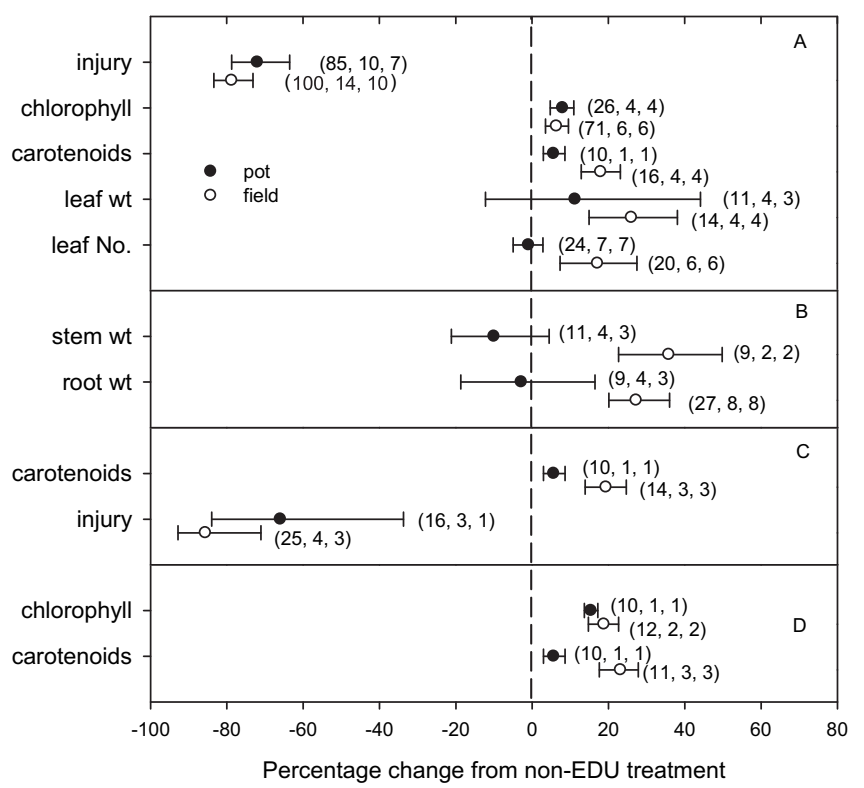

Fig. 3. Effects of rooting environment on the protection of EDU on plants exposed to ambient $\left[\mathrm{O}_{3}\right]$ across all observations (A), across crops applied as a soil drench or a foliar spray of EDU (B), across crops applied as a soil drench of EDU (C), across crops applied as a soil drench of EDU at a concentration of $201-400 \mathrm{mg} / \mathrm{L}$ (D). Symbols represent the mean percentage change induced by EDU relative to non-EDU treatment and the bars show the 95\% confidence intervals (CIs). The values in the parentheses showed the number of observations, individual studies and species, respectively. 
per plant (Fig. 4A), yield and grain/seed No. per ear/pod (Fig. 4B) of crops rooted in the field, and in leaf number of plants rooted in the pots (Fig. 4C). For crops rooted in the field and applied the 201-400 mg/L of EDU, the increases in yield and grain/seed No. by a soil drench were 6 -fold and 10 -fold of those by a foliar spray, respectively (Fig. 4B).

\subsection{The effect of EDU concentrations}

From the dataset of crops rooted in the field, most variables did not show significant difference among EDU concentrations (Fig. 5), except crop height (Fig. 5A), Chl and yield (Fig. 5B) with a larger effects of $201-400 \mathrm{mg} / \mathrm{L} \mathrm{EDU}$ (B level) than that of $401-600 \mathrm{mg} / \mathrm{L}$ (C level).

\subsection{The difference in response of yield and its components between crops}

There was no significant difference in response of yield to EDU between crop species (Fig. 6A). The largest increase due to EDU was found in wheat (19.5\%) and soybean (19.4\%), with a 95\% CI from $12.8 \%$ to $28.0 \%$ (wheat) and from $7.1 \%$ to $35.6 \%$ (soybean).

Response of yield components to EDU treatment varied with species (Fig. 6B, C, D). For example, for bean plants only their seed weight increased significantly (3.8\%) after EDU application, while for soybean, EDU increased pod number significantly (61\%) and single seed weight by $11.3 \%$. For wheat, EDU induced significant increase only in ear number per plant $(20.8 \%)$ and had no effects on individual grain weight and grain number per ear. There were no significant differences among wheat, potato, bean and tomato in ear/tuber/pod/fruit number per plant (Fig. 6B).

\section{Discussion}

This meta-analysis demonstrated that EDU application is very effective in reducing $\mathrm{O}_{3}$-caused visible injury (76\%) of the investigated plant species in comparison with non-EDU (water) treated plants. In all studies included in this database, the plants were

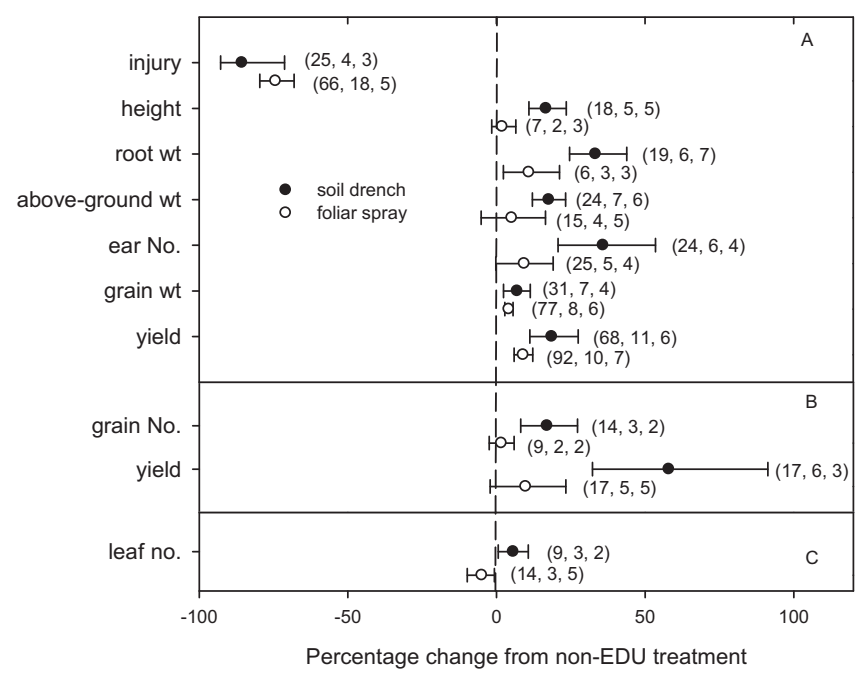

Fig. 4. Effects of different EDU application methods on plants grown under ambient $\left[\mathrm{O}_{3}\right]$, specified as crops rooted in the field $(\mathrm{A})$, crops rooted in the field and applied EDU at a concentration of $201-400 \mathrm{mg} / \mathrm{L}^{-1}$ (B), and number of leaves of crops and grasses rooted in the pot $(C)$. Symbols represent the mean percentage change induced by EDU relative to non-EDU treatment and the bars show the 95\% confidence intervals (CIs). The values in the parentheses showed the number of observations, individual studies and species, respectively.

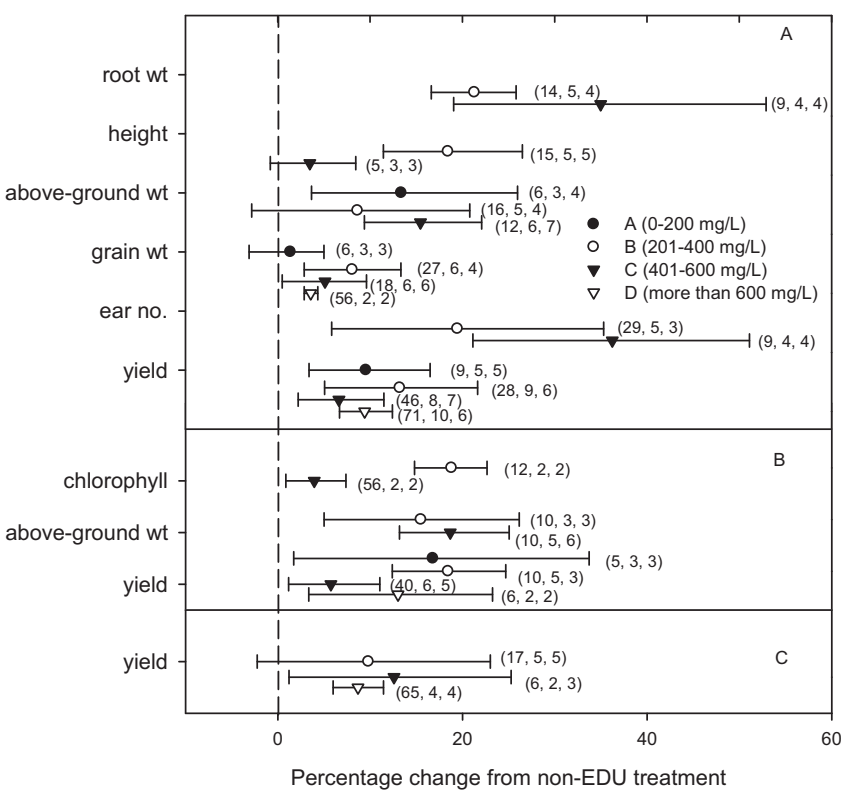

Fig. 5. Effects of different EDU concentration on crops exposed to ambient $\left[\mathrm{O}_{3}\right]$, specified as crops rooted in the field (A), crops rooted in the field and applied as a soil drench of EDU (B) and crops rooted in the field and applied as foliar spray of EDU (C). Symbols represent the mean percentage change induced by EDU relative to non-EDU treatment and the bars show the 95\% confidence intervals (CIs). The values in the parentheses showed the number of observations, individual studies and species, respectively.

exposed to ambient $\left[\mathrm{O}_{3}\right]$ ranging from $30 \mathrm{ppb}$ to $85 \mathrm{ppb}$ in open-air conditions ( $90 \%$ of all studies) or OTCs ( $10 \%$ of all studies). The reduction in the visible injury caused by EDU was also observed in a review on crops and trees in Italy, exposed to ozone in controlled

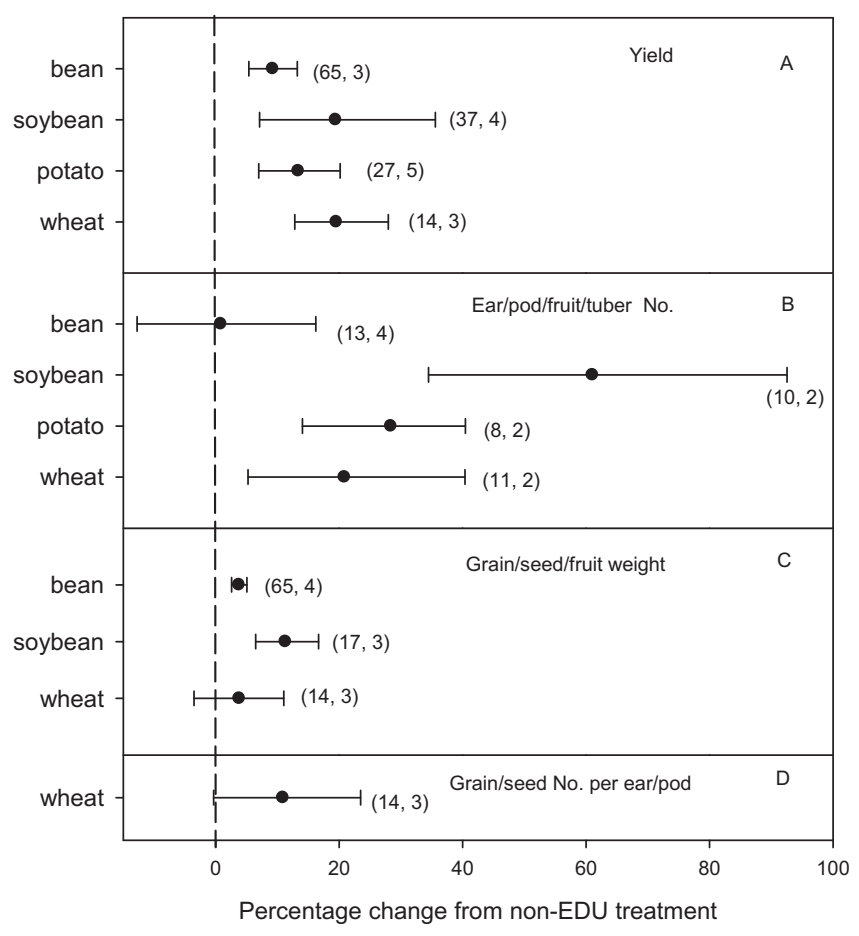

Fig. 6. Effects of EDU on yield and its components of field-rooted crops grown under ambient $\left[\mathrm{O}_{3}\right]$. Symbols represent the mean percentage change induced by EDU relative to non-EDU treatment and the bars show the $95 \%$ confidence intervals (CIs). The values in the parentheses showed the number of observations and individual studies, respectively. 
chambers (50-300 ppb) or to ambient condition (Paoletti et al., 2009). EDU protection was not complete, as visible injury was reduced but not avoided in most observations. Amelioration of visible injury was achieved by regularly applying EDU at two or three week intervals along $\mathrm{O}_{3}$ exposure. Repeated application of EDU is necessary for protection against $\mathrm{O}_{3}$ injury due to the fact that EDU stays for a relatively short period after application (Carnahan et al., 1978) and no mobilization of EDU occurs from old leaves to new leaves (Weidensaul, 1980).

From the overall results, morphological characteristics showed significant improvements due to EDU application in plants. This result supports the conclusion that current ambient $\left[\mathrm{O}_{3}\right]$ had significant negative effects on plant growth (Booker et al., 2009; Fuhrer, 2009; Wittig et al., 2009). Most importantly, EDU could increase yield of crops by $15 \%$ with a $95 \%$ CI of $11.3-19.0 \%$, suggesting that current ambient $\left[\mathrm{O}_{3}\right]$ significantly causes yield loss in food, fruit and economic crops (Booker et al., 2009; Feng and Kobayashi, 2009). The higher yield in EDU-treated plants was largely attributed to significant increase in the ear/pod/tuber number per plant, although grain/seed number per ear/pod and individual grain/seed/tuber weight were also increased.

EDU was applied as a soil drench or a foliar spray to crops, soil drench to grasses and stem injection or infusion to trees, thus, we cannot compare the differences in response to EDU between plant types. However, available information helps us to understand the response level of each type of plant to EDU at current $\left[\mathrm{O}_{3}\right]$ conditions. Considering many factors affecting the final output of any variables, we try to compare within each category on the basis of similar growth condition and EDU application. Direct comparisons were also done on crops as a result of enough observations. Observations in some variables were limited $(\leq 10)$ after strict selection, so larger variation occurred in some categorical comparisons. In some cases, larger variation also depended on species, varieties and ambient $\left[\mathrm{O}_{3}\right]$, although the method and/or concentrations of EDU applications were similar, e.g. pod number in soybean (Fig. 6B). A soybean variety (cv. NARC-1) in Pakistan showed much more pod numbers (between $84 \%$ and 156\%) after soil drench of $400 \mathrm{mg} / \mathrm{L} \mathrm{EDU}$, relative to non-EDU treatment (Wahid et al., 2001), whereas in the other study in Egypt, the soybean (cv. Crawford) only showed 10\% increase after soil drench of $350 \mathrm{mg} / \mathrm{L}$ EDU (Ali and Abdel-Fattah, 2006).

More than $70 \%$ of all studies included in this paper investigated effects of EDU on crops, covering 15 species, possibly due to the fact that crops are easier to be treated with EDU than trees, as well as food production and security play a very important role from the global view, especially with the rapid increase in human population. This large database on crops provides us a chance to determine whether the effects of EDU were affected by other factors such as rooting environment, EDU application methods and EDU concentrations. EDU significantly increased biomass and yield of crops exposed to ambient [ $\mathrm{O}_{3}$ ] (Fig. 2). The ameliorative effects of EDU largely depended on the rooting environment and application method rather than on EDU concentration or on crop species, as seen from comparisons based on different criteria (Figs. 3-6), especially from direct comparisons like Figs. 3D and 4B. From the available comparisons on four concentrations of EDU, only level B (201-400 mg/L) showed significantly better effects on some variables (e.g. Chl and yield) than level C (401-600 mg/L), while there was no significant difference between levels A, B or D. Since much more observations were obtained from levels $B$ and $C$ relative to levels A and D, 201-400 mg/L of EDU was assumed to be the best concentration to assess effects of EDU on crops. From the mean response, it can be inferred that EDU applied as a soil drench at a concentration of $201-400 \mathrm{mg} / \mathrm{L}$ has a maximum positive impact on crops grown in the field.
In contrast to a large range of crops species, only three grass species (Trifolium subterraneum, Trifolium repens, Trifolium pretense) were studied at ambient $\left[\mathrm{O}_{3}\right]$ and very few variables (visible injury, yield and leaf number) were investigated. Notably, the classification was a little different from that of ICP vegetation, where T. subterraneum belongs to crops. Most observations were from the framework of the United Nations/Economic Commission for Europe International Co-operative Programme (UN/ECE ICP-Vegetation) on the effects of air pollution and other stresses on crops and non-woody plants. Therefore nearly all studies used the same concentration (150 mg/L EDU) applied as a soil drench to potted clover. This meta-analysis indicated that EDU could significantly protect clover from ambient $\left[\mathrm{O}_{3}\right]$, as less visible injury and greater yield was documented. This result supported clover as a good indicator in $\mathrm{O}_{3}$ research.

From this analysis, we found that EDU was unable to significantly ameliorate $\mathrm{O}_{3}$ effects on tree height and biomass of different organs, whereas stem diameter and foliar Chl content were increased significantly. The results differed from a review on tree species (Populus $\times$ euramericana 'I-214', Populus deltoides $\times$ maximowiczii 'Eridano' and Fraxinus excelsior) in Italy, exposed to ambient open-air or closed chambers, where EDU reduced $\mathrm{O}_{3}$ effects on shoot growth but had no effects on stem diameter (Paoletti et al., 2009). This database included studies of Long and Davis (1991) and Bortier et al. (2001).In these studies significant increase in stem diameter was observed on EDU-treated plants. Relative to tree ages, the duration of EDU application was short, most with one or two growing seasons. Only one research lasted for four years, in which EDU-treated Prunus serotina Ehrh was $17 \%$ taller and stem diameters were $21 \%$ greater than non-EDU plants (Long and Davis, 1991). In contrast to grasses and crops, it is difficult to apply EDU to a full-grown tree. Foliar spray and soil drench would require a prohibitive amount of EDU to treat large trees in the field. Stem injection or infusion requires making an entry hole in a tree trunk, which caused wounds and could be easily attacked by pests. To date, only few studies reported the effects of EDU on trees, although the use of EDU showed great potential in the study of $\mathrm{O}_{3}$ effects on trees (Manning, 2005). Paoletti et al. (2009) suggested that developing an effective soil application method for full-grown trees is needed.

This meta-analysis indicated that EDU did not modify the stomatal conductance of plants in comparison with non-EDU treatment, suggesting that antiozonant activity of EDU is biochemical rather than biophysical in nature. Significant increments in foliar Chl content and Pn of EDU-treated plants suggested that EDU delays the senescence in leaves of plants. Most works indicated that the maintenance in activity of antioxidant enzymes, especially ascorbate peroxidase and high levels of ascorbic acid were assumed to be responsible for the protective effect of EDU (Brunschiin-Harti et al., 1995; Paoletti et al., 2009; Tiwari and Agrawal, 2009). However, the mode of action of EDU remains disputed or unconfirmed (Paoletti et al., 2009).

In the last decade, meta-analysis was very popular in assessing the effects of $\mathrm{O}_{3}$ on vegetation, including trees (Valkama et al., 2007; Wittig et al., 2007, 2009), semi-natural species (Hayes et al., 2007) and crops (Ainsworth, 2008; Feng and Kobayashi, 2009; Feng et al., 2008; Morgan et al., 2003). Notably, all above mentioned meta-analysis were based on observations in chambers or greenhouses. In a meta-analysis on chamber results, current ambient $\left[\mathrm{O}_{3}\right]$ significantly reduced the above-ground biomass of trees by 7\% in comparison with CF air (Wittig et al., 2009). EDU increased the above-ground biomass by $6.5 \%$ for trees grown in ambient open-air, indicating similar effects of ambient $\left[\mathrm{O}_{3}\right]$ on trees through EDU application in open-air and ambient air filtrated in chambers. 
Relative to $\mathrm{CF}$ air, ambient $\left[\mathrm{O}_{3}\right]$ caused a mean yield loss of $10.2 \%$ in the range from $3 \%$ to $19 \%$ in the four major food crops (wheat, potato, bean and soybean) rooted in the field (Feng and Kobayashi, 2009). This meta-analysis indicated that EDU significantly increased yield of crops rooted in the field by $15.2 \%$ with a range from $9 \%$ to $20 \%$ (Fig. $6 \mathrm{~A}$ ). The large difference may be strongly related with selected cultivars and other environmental factors, such as elevated $\mathrm{CO}_{2}$ and drought. In this study, the varieties in south Asia were found very sensitive to ambient $\left[\mathrm{O}_{3}\right]$, which was also observed by Emberson et al. (2009). In rural areas of Pakistan with $\left[\mathrm{O}_{3}\right]$ of $48-75 \mathrm{ppb}$, the yields in EDU-treated soybean were $110 \% \sim 282 \%$ higher than those in non-EDU treated ones (Wahid et al., 2001). In India, EDU increased yield in two varieties of wheat by $20 \%$ in average where the maximum increase reached $66 \%$ (Tiwari et al., 2005). Elevated $\left[\mathrm{CO}_{2}\right]$ or drought has been reported to significantly lessen $\mathrm{O}_{3}$-induced yield loss (Feng et al., 2008; Morgan et al., 2003). The meta-analysis based on chamber results included the interactive effects of $\mathrm{O}_{3}$ and elevated $\left[\mathrm{CO}_{2}\right]$ or $\mathrm{O}_{3}$ and drought (Feng and Kobayashi, 2009). However, the effects of EDU were investigated only in the ambient air condition without other environmental factors. In spite of differences between EDU technique and chamber filtration, all these meta-analysis indicated current $\left[\mathrm{O}_{3}\right]$ has caused significant negative effects on the growth of plants, covering crops, grasses and trees.

\section{Conclusion}

This meta-analysis quantitatively evaluated the effects of EDU on the growth of 24 species including crops (15), grasses (3) and trees (6), exposed to ambient $\left[\mathrm{O}_{3}\right]$ in open-air (90\% of all studies) and in OTCs (10\% of all studies). EDU application was very effective in reducing $\mathrm{O}_{3}$-caused visible injury and significantly increased biomass of plants and yield of crops in comparison with non-EDU treatment, suggesting that ozone is causing losses in the growth and yield of plants under current ambient conditions.

From the mean response, EDU applied as a soil drench at a concentration of $201-400 \mathrm{mg} / \mathrm{L}$ has a maximum positive impact on crops grown in the field. EDU applied as a soil drench at $150 \mathrm{mg} / \mathrm{L}$ could significantly protect clover from ambient $\left[\mathrm{O}_{3}\right]$. Based on the available data, the authors cannot conclude which EDU method or concentration was the best for the growth of trees. Long-term research on full-grown tree species is needed. Overall, EDU is a powerful tool for assessing effects of ambient $\left[\mathrm{O}_{3}\right]$ on vegetation.

\section{Acknowledgements}

This study was supported by the National Nature Science Foundation of China (No. 30700086) and Special Project for Environmental Protection Sector, China (200809152). The authors thank Dr. William J. Manning (University of Massachusetts) for his suggestions and improvement on this manuscript. We would like to acknowledge authors of primary data for their hard work and detailed report.

\section{Appendix. Supplementary material}

Supplementary data associated with this article can be found in the online version at doi:10.1016/j.envpol.2010.07.009.

\section{References}

Adams, D.C., Gurevitch, J., Rosenberg, M.S., 1997. Resampling tests for meta -analysis of ecological data. Ecology 78, 1277-1283.

Agrawal, S.B., Singh, A., Rathore, D., 2005. Role of ethylenediurea (EDU) in assessing impact of ozone on Vigna radiata L. plants in a suburban area of Allahabad (India). Chemosphere 61, 218-228.
Ainsworth, E.A., 2008. Rice production in a changing climate: a meta-analysis of responses to elevated carbon dioxide and elevated ozone concentration. Global Change Biology 14, 1642-1650.

Ali, A.A., Abdel-Fattah, R.I., 2006. Protection of agricultural crops in Egypt against adverse effects of atmospheric pollutants I. by using of ethylene diurea. Journal of Agronomy 5, 158-166.

Ashmore, M.R., 2005. Assessing the future global impacts of ozone on vegetation. Plant Cell and Environment 28, 949-964.

Ball, G.R., Benton, J., Palmer-Brown, D., Fuhrer, J., Skarby, L., Gimeno, B.S., Mills, G., 1998. Identifying factors which modify the effects of ambient ozone on white clover (Trifolium repens) in Europe. Environmental Pollution 103, 7-16.

Booker, F., Muntifering, R., McGrath, M., Burkey, K., Decoteau, D., Fiscus, E., Manning, W.J., Krupa, S., Chappelka, A., Grantz, D., 2009. The ozone component of global change: potential effects on agricultural and horticultural plant yield, product quality and interactions with invasive species. Journal of Integrative Plant Biology 51, 337-351.

Bortier, K., Dekelver, G., De Temmerman, L., Ceulemans, R., 2001. Stem injection of Populus nigra with EDU to study ozone effects under field conditions. Environmental Pollution 111, 199-208.

Brunschiin-Harti, S., Fangmeier, A., Jäger, H., 1995. Effects of ethylenediurea and ozone on the antioxidative systems in beans (Phaseolus vulgaris L.). Environmental Pollution 90, 95-103.

Carnahan, J.E., Jenner, E.L., Wat, E.K.W., 1978. Prevention of ozone injury to plants by a new protectant chemical. Phytopathology 68, 1222-1229.

Curtis, P.S., Wang, X., 1998. A meta-analysis of elevated $\mathrm{CO}_{2}$ effects on woody plant mass, form, and physiology. Oecologia 113, 299-313.

Emberson, L.D., Buker, P., Ashmore, M.R., Mills, G., Kackson, L.S., Agrawal, M., Atikuzzaman, M.D., Cinderby, S., Engardt, M., Jamir, C., Kobayashi, K., Oanh, N.T.K., Quadir, Q.F., Wahid, A., 2009. A comparison of North American and Asian exposure-response data for ozone effects on crop yields. Atmospheric Environment 43, 1945-1953.

Feng, Z.Z., Kobayashi, K., 2009. Assessing the impacts of current and future concentrations of surface ozone on crop yield with meta-analysis. Atmospheric Environment 43, 1510-1519.

Feng, Z.Z., Kobayashi, K., Ainsworth, E.A., 2008. Impact of elevated ozone concentrationon growth, physiology and yield of wheat (Triticum aestivum L.): a metaanalysis. Global Change Biology 14, 2696-2708.

Feng, Z.Z., Pang, J., Kobayashi, K., Zhu, J.G., Ort, D.R., 2010. Differential responses in two varieties of winter wheat to elevated ozone concentration under fully open-air field conditions. Global Change Biology. doi:10.1111/j.1365-2486.2010. 02184.x.

Fuhrer, J., 2009. Ozone risk for crops and pastures in present and future climates. Naturwissenschaften 96, 173-194.

Fuhrer, J., Booker, F., 2003. Ecological issues related to ozone: agricultural issues. Environment International 29, 141-154.

Hayes, F., Jones, M.L.M., Mills, G., Ashmore, M., 2007. Meta-analysis of the relative sensitivity of semi-natural vegetation species to ozone. Environmental Pollution 146, 754-762.

Hedges, L.V., Gurevitch, J., Curtis, P.S., 1999. The meta-analysis of response ratios in experimental ecology. Ecology 80, 1150-1156.

Holland, M.R., Mueller, P.W., Rutter, A.J., Shaw, P.J.A., 1995. Growth of coniferous trees exposed to $\mathrm{SO}_{2}$ and $\mathrm{O}_{3}$ using an open-air fumigation system. Plant, Cell and Environment 18, 227-236.

Lei, X.D., Peng, C.H., Tian, D.L., Sun, J.F., 2007. Meta-analysis and its application in global change research. Chinese Science Bulletin 52, 289-302.

Long, R.P., Davis, D.D., 1991. Black Cherry growth response to ambient ozone and EDU. Environmental Pollution 70, 241-254.

Manning, W.J., 2000. Use of protective chemicals to assess the effects of ambient ozone on plants. In: Agrawal, S.B., Agrawal, M. (Eds.), Environmental Pollution and Plant Responses. Lewis Publishers, Boca Raton, FL, pp. 247-258.

Manning, W.J., 2005. Establishing a cause and effect relationship for ambient ozone exposure and tree growth in the forest: progress and an experimental approach. Environmental Pollution 137, 443-454.

Mills, G., Hayes, F., Simpson, D., Emberson, L., Norris, D., Harmens, H., Buker, P., 2010. Evidence of widespread effects of ozone on crops and (semi-)natural vegetation in Europe (1990-2006) in relation to AOT40 - and flux-based risk maps. Global Change Biology. doi:10.1111/j.1365-2486.2010.02217.x.

Morgan, P.B., Ainsworth, E.A., Long, S.P., 2003. How does elevated ozone impact soybean? A meta-analysis of photosynthesis, growth and yield. Plant, Cell and Environment 26, 1317-1328.

Nussbaum, S., Fuhrer, J., 2000. Difference in ozone uptake in grassland species between open -top chambers and ambient air. Environmental Pollution 109, $463-471$.

Osenberg, C.W., Sarnelle, O., Cooper, S., Holt, R.D., 1999. Resolving ecological questions through meta-analysis: goals, metrics and models. Ecology 80, 1105-1117.

Paoletti, E., Contran, N., Manning, W.J., Castagna, A., Ranieri, A., Tagliaferro, F., 2008. Protection of ash (Fraxinus excelsior) trees from ozone injury by ethylenediurea (EDU): roles of biochemical changes and decreased stomatal conductance in enhancement of growth. Environmental Pollution 155, 464-472.

Paoletti, E., Contran, N., Manning, W.J., Ferrara, A.M., 2009. Use of the antiozonant ethylenediurea (EDU) in Italy: verification of the effects of ambient ozone on crop plants and trees and investigation of EDU's mode of action. Environmental Pollution 157, 1453-1460. 
Piikki, K., De Temmerman, L., Högy, P., Pleijel, H., 2008a. The open -top chamber impact on vapour pressure deficit and its consequences for stomatal ozone uptake. Atmospheric Environment 42, 6513-6522.

Piikki, K., De Temmerman, L., Ojanpera, K., Danielsson, H., Pleijel, H., 2008b. The grain quality of spring wheat (Triticum aestivum L.) in relation to elevated ozone uptake and carbon dioxide exposure. European Journal of Agronomy 28, 245-254.

Roberts, B.R., Jensen, K.F., Cathey, H.M., 1985. Modification of ozone sensitivity in seedlings by ethylenediurea: soil application vs. stem injection. Journal of the American Society for Horticultural Science 110, 178-180.

Rosenberg, M.S., Adams, D.C., Gurevitch, J., 2000. Metawin: Statistical Software for Meta -Analysis, Version 2.1. Sinauer Associates, Inc, Sunderland, MA, USA.

Sanders, G.E., Booth, C.E., Weigel, H.J., 1992. The use of EDU as a protectant against ozone pollution. Air Pollution Research Report 46. In: Jäger, H.J., Unsworth, M. De Temmerman, L., Mathy, M. (Eds.), Effects of Air Pollution on Agricultural Crops in Europe: Results of the European Open-top Chambers Project. Commission of the European Communities, Brussels, pp. 359-369.

Singh, S., Agrawal, S.B., Agrawal, M., 2009. Differential protection of ethylenediurea (EDU) against ambient ozone for five cultivars of tropical wheat. Environmental Pollution 157, 2359-2367.

The Royal Society, 2008. Ground-level Ozone in the 21st Century: Future Trends, Impacts and Policy Implications. Science Policy Report 15/08. The Royal Society, London.

Tiwari, S., Agrawal, M., 2009. Protection of palak (Beta vulgaris L. var Allgreen) plants from ozone injury by ethylenediurea (EDU): roles of biochemical and physiological variations in alleviating the adverse impacts. Chemosphere 75, 1492-1499.
Tiwari, S., Agrawal, M., Manning, W.J., 2005. Assessing the effects of ambient ozone on growth and productivity of two cultivars of wheat in India using three rates of application of ethylenediurea (EDU). Environmental Pollution 138, 153-160.

Valkama, E., Koricheva, J., Oksanen, E., 2007. Effects of elevated $\mathrm{O}_{3}$, alone and in combination with elevated $\mathrm{CO}_{2}$, on tree leaf chemistry and insect herbivore performance: a meta-analysis. Global Change Biology 13, 184-201.

Vingarzan, R., 2004. A review of surface ozone background levels and trends. Atmospheric Environment 38, 3431-3442.

Wahid, A., Miline, E., Shamsi, S.R.A., Ashmore, M.R., Marshall, F.M., 2001. Effects of oxidants on soybean growth and yield in the Pakistan Punjab. Environmental Pollution 113, 271-280.

Wang, X.K., Manning, W.J., Feng, Z.W., Zhu, Y.G., 2007. Ground-level ozone in China: distribution and effects on crop yields. Environmental Pollution 147, 394-400.

Weidensaul, T.C., 1980. N-[2-(2-oxo-1-imidizolidiny1) ethyl-]-N'-phenylurea as a protectant against ozone injury to laboratory fumigated pinto bean plants. Phytopathology 70, 42-45.

Wittig, V.E., Ainsworth, E.A., Long, S.P., 2007. To what extent do current and projected increases in surface ozone affect photosynthesis and stomatal conductance of trees? A meta-analytic review of the last 3 decades of experiments. Plant Cell and Environment 30, 1150-1162.

Wittig, V.E., Ainsworth, E.A., Naidu, S.L., Karnosky, D.F., Long, S.P., 2009. Quantifying the impact of current and future tropospheric ozone on tree biomass, growth, physiology and biochemistry: a quantitative meta-analysis. Global Change Biology 15, 396-424. 